\title{
ОСОБЕННОСТИ ЭМОЦИОНАЛЬНОГО ИНТЕЛЛЕКТА ПОДРОСТКОВ С РАЗНОЙ СТЕПЕНЬЮ УВЛЕЧЕННОСТИ КОМПЬЮТЕРНЫМИ ИГРАМИ
}

\section{FEATURES OF EMOTIONAL INTELLIGENCE OF TEENAGERS WITH DIFFERENT DEGREES OF INTEREST IN COMPUTER GAMES \\ I. Petrochenko I. Shchelin}

Summary: The article is devoted to the study of the emotional intelligence of adolescents with varying degrees of interest in computer games. Specific features of the emotional intelligence of adolescents with a natural level of passion, an average level of passion and dependence on computer games were identified. The results of the study will be useful not only for teachers and psychologists working with this age group, but also for parents of adolescents in order to prevent the development of psychological dependence of adolescents on computer games.

Keywords: addiction, computer games, teenagers, passion, emotional intelligence.

\section{Введение}

$\mathrm{B}$ общении, идентификации и самоактуализации подростка особое влияние придается именно эмоциональной сфере. Умение понимать свои чувства в данный момент и эмоции окружающих его людей, способствует эффективной адаптации подростка к социальной жизни. Но стремительное усовершенствование информационных технологий начинает оказывать свое влияние и на подрастающее поколение. Реальное общение стало заменяться виртуальным, а вместо взаимодействия со сверстниками в реальной жизни, подростки все чаще прибегают к общению в социальных сетях и компьютерных играх. Каждый подросток имеет большое количество социальных связей и контактов в виртуальном мире, но при этом изменяются его способности к эмпатии, осознанию чувств и регулированию собственных эмоций в реальном мире [11].

Эмоциональная сфера оказывает влияние на все сферы деятельности подростков. Формирование и полноценное развитие эмоционального интеллекта в этом возрасте позволяет человеку в дальнейшем адаптироваться к новым ситуациям, к жизни в обществе в целом и успешно взаимодействовать с окружающими людьми. Однако развитие эмоциональной сферы современных

\begin{abstract}
Петроченко Ирина Алексеевна
Национальный Исследовательский Томский Государственный университет, г. Томск Irina-Petrochenko22@yandex.ru щелин Игорь Владимирович

К.nсх.н., доцент, Национальный Исследовательский Томский Государственный университет, г. Томск shchelin@rambler.ru

Аннотация: Статья посвящена исследованию эмоционального интеллекта подростков с разной степенью увлеченности компьютерными играми. Были выявлены специфические особенности эмоционального интеллекта подростков с естественным уровнем увлечения, средним уровнем увлечения и зависимостью от компьютерных игр. Результаты исследования будут полезны не только педагогам и психологам, работающим с данной возрастной группой, но и родителям подростков с целью профилактики развития психологической зависимости подростков от компьютерных игр.
\end{abstract}

Ключевые слова: зависимость, компьютерные игры, подростки, увлеченность, эмоциональный интеллект.

подростков находится под влиянием компьютерных технологий.

Современные подростки практически полностью вовлечены в ту жизнь, которая происходит за экраном их телефонов или компьютеров. Умение подростков взаимодействовать друг с другом посредством современных технологий сказывается на их функционировании в реальной жизни.

Помимо социальных сетей по частоте использования оборот набирают и компьютерные игры. И важным вопросом в исследовании данной проблемы является последствия увлеченности компьютерными играми. В научных исследованиях указывается вероятностная возможность появления патологической формы увлечения близкой к поведенческой зависимости, проявляющаяся в изоляции подростка от внешнего мира, проявлении агрессивности, тревожности и разрушении значимых социальных связей.

Так, в исследовании эмоциональных последствий компьютерной игры В. С. Собкин и Ю. М. Евстигнеева установили, что у небольшой части играющих возникает агрессивное состояние после окончания игры [17]. М.И.Иванов с установил, что у подростков, которые 
обращаются к компьютерными играм, после игры ухудшается настроение и снижается общий эмоциональный фон [6].

В своем исследовании Л.Н. Никитина выделила три основные группы последствий, возникающие в результате чрезмерного увлечения компьютерными играми [12].

Первая группа - последствия на физиологическом плане:

- проблемы с режимом сна и бодрствования;

- потеря аппетита и нерегулярное питание;

- проблемы со зрением, выражающиеся в сухости и жжении глаз;

- проблемы с позвоночником;

- пренебрежение личной гигиеной.

Вторая группа - это изменения, происходящие на психологическом уровне, которые несут в себе большую опасность для психики подростка и являются симптомами возникновения психологической зависимости от игр.

Третья группа включает в себя последствия, проявляющиеся на социальном уровне:

- частые конфликты с родителями и учителями;

- снижение учебной успеваемости;

- отсутствие других увлечений и хобби кроме компьютерных игр;

- время, потраченное на прохождение игры, становится предпочтительнее живому общению;

- социальная дезадаптация;

- готовность нарушить закон ради игры.

Более подробно рассмотрим вторую группу последствий увлеченности компьютерными играми:

1. частичная или полная идентификация подростка с компьютерными героями. Как считает М.С. Иванов, именно ролевые игры являются одним из существенных факторов формирования игровой зависимости [14].

По мнению П.А. Мунтян, полная идентификация подростков с виртуальным персонажем происходит за счет специфических особенностей игры. Невыполнение какой-либо задачи в игре не несет серьезных последствий в реальной жизни. Ошибка в игре легко исправляется многоразовым прохождением конкретного этапа игрового процесса [14]. А.М. Демильхановой было отмечено, что во время игрового процесса происходит разделение внешнего «Я», которое находится за экраном компьютера, и внутреннего «Я», т.е. «Я» как субъекта деятельности. Именно интерес подростка к ролевым играм приводит к изменению восприятия собственного образа «я» и ведет к тому, что подросток идентифицирует себя персонажем игры и наделяет себя теми же качествами, что и выдуман- ный герой [5].

Причинами идентификации подростка с персонажами компьютерной игры является удовлетворение собственных потребностей. Ведь примеряя на себя роль сильного и смелого героя, подростки тем самым преодолевают свою слабость и чувство неполноценности. С проявлением идентификации также связаны такие защитные механизмы, как замещение, рационализация и отрицание [12].

2. негативное отношение к себе в результате рассогласования и появление большого разрыва «Я-реального» от «Я-виртуального». Конфликтное состояние между «Я-реальным» и «Я-виртуальным», по мнению М.С. Иванова, может привести к нарушениям психических состояний подростка, а также вызвать усиление социальной дезадаптации [14].

В процессе игры у подростка возникает чувство комфорта и безопасности, а также появляется ощущение превосходства и властности. Но комфортное состояние резко сменяется при выходе в реальную жизнь, где есть нерешенные проблемы и отсутствие высокого статута в группе. В результате подросток стремится вернуться в зону комфорта и все больше погружается в игровой мир.

3. понимание того, что игры отнимают много сводного времени и не приносят желаемого результата, но невозможность быстро прекратить. Большая часть людей, для которых компьютерные игры являются хобби, отмечали, что игры также вредят их здоровью и близким межличностным отношениям. Как отмечает М.С. Иванов, люди, даже после осознания бесполезности игровой деятельности, не могли полностью отказаться от нее, что в дальнейшем приводило к возникновению не поддающейся изменениям психологической зависимости от компьютерных игр [14].

4. нарушение эмоционально-волевой сферы подростка. Эмоциональный интерес усиливается к героям игры, но ослабевает интерес к социальным контактам с окружающими в реальной жизни.

Результаты исследования Л.Н. Никитиной указывают на то, что подросткам, чрезмерно увлекающимся компьютерными играми, свойственен высокий уровень тревожности. Автор объясняет выявленную особенность двумя факторами. Первый фактор указывает на то, что, играя за смелого и непобедимого героя, несовершеннолетние тем самым компенсируют чувство страха и тревоги, проявляющиеся в реальности. Второй фактор связан с тем, что постоянное желание победить, переживание очень близких к реальности сцен, приводят к тому, что подростки находятся в состоянии напряжения и тревоги за жизнь героя.

Проведенный теоретический анализ литературы 
говорит о том, что чрезмерная увлеченность компьютерными играми приводит к негативным последствиям, которые затрагивают когнитивную, эмоциональную, поведенческую и физиологическую сферы развития личности подростка. Большинство современных психологических исследований по данной проблематике направлены на изучение патологической зависимости от игр $[3,13,18]$, в то время как остается слабо изученным состояние предзависимости или сильной увлеченности, при котором изменения в структуре личности не являются глобальными и поддаются коррекции. Детальное изучение сущности, причин и последствий увлеченности компьютерными играми создаст возможности для осуществления профилактических мер относительно патологической зависимости подростков от компьютерных игр.

Актуальность данной работы обусловлена специфическими особенностями эмоционального интеллекта подростков, увлекающихся компьютерными играми, с целью профилактики развития психологической зависимости подростков от компьютерных игр.

Гипотеза исследования заключается в том, что подростки с разной степенью увлеченности компьютерными играми обладают специфическими особенностями эмоционального интеллекта.

\section{Методы}

С целью изучения эмоционального интеллекта подростков с разной степенью увлеченности компьютерными играми было проведено эмпирическое исследование, в котором приняли участие 90 подростков (50 мальчиков и 40 девочек) в возрасте 14 - 16 лет. Все респонденты - учащиеся 9-х классов МБОУ «Средняя общеобразовательная школа № 16» г. Березовский, Кемеровской области

В своей работе мы опирались на теории эмоционального интеллекта: модель способностей Дж. Мэйера, П. Сэловея и Д. Карузо [16], модель эмоционального интеллекта Д. Гоулмана [2], модель эмоционального интеллекта Р. Бар-Она [1] в зарубежной психологии, а также на модель эмоционального интеллекта Д.В. Люсина [10], модель М.А. Манойловой [11], модель Э.Л. Носенко и Н.В. Ковриги [1] в отечественной психологии.

Использовались теоретические представления о динамике формирования компьютерной зависимости Л.Н. Юрьева и Т.Ю. Больбот [19], которые выделили четыре стадии формирования зависимости от компьютерных игр:

1. стадия легкой увлеченности, при которой обращение к компьютерным играм носит ситуативных характер, устойчивая и постоянная потребность в игре не сформирована.
2. стадия увлеченности - стадия, в которой компьютерные игры занимают одну из ведущих положений в системе потребностей человека.

3. стадия психологической зависимости характеризуется серьезными изменениями индивидуальных особенностей человека, его иерархии ценностей и самооценки.

\section{Организашия исследования}

Эмпирический сбор данных осуществлялся в декабре 2019 - январе 2020 года.

Для исследования эмоционального интеллекта подростков с разной степенью увлеченности компьютерными играми использовался комплекс методик:

- Опросник эмоционального интеллекта «ЭмИн» Д.В. Люсина [9];

— «Тест на эмоциональный интеллект» Н. Холла [7];

- «Тест-опросник степени увлеченности компьютерными играми» А. В. Гришиной [4];

- Методы математической статистики: t-критерий Стьюдента для независимых выборок.

\section{Результаты}

Рассмотрим данные, полученные при проведении сравнения средних значений показателей эмоционального интеллекта, полученных с помощью методик «ЭмИн» Д.В. Люсина и теста на эмоциональный интеллект Н. Холла, у подростков с разным уровнем увлечения компьютерными играми. Полученные значимые результаты представлены в Таблицах 1-3.

Полученные данные из Таблицы 1 указывают на то, что игра на естественном уровне увлечения носит лишь развлекательный и краткосрочный характер, поэтому подростки меньше тратят свое время на компьютерные игры и больше проводят время с окружающими людьми, поэтому это положительно сказывается на их способности к пониманию эмоций и контролю эмоциональный состояний как у себя, так и у других людей посредством мимики, жестов, интонаций и т.п.

Таблица 2 указывает на то, что подростки со средним уровнем увлечения обладают большим значением показателей эмоционального интеллекта, чем подростки с зависимостью от компьютерных игр. Чем ближе увлечение компьютерными играми к зависимости от игр у подростков, тем ниже показатели эмоционального интеллекта. То есть подростки со средним уровнем увлеченности компьютерными играми лучше осознают свои эмоции и эмоции окружающих людей, а также могут их контролировать по сравнению с подростками, зависимыми от компьютерных игр. Все это может сказаться на способности подростков поддерживать и устанавливать 
Таблица 1.

Результаты сравнений средних значений показателей эмоционального интеллекта подростков с естественным и средним уровнем увлечения компьютерными играми

\begin{tabular}{|l|c|c|c|c|}
\hline \multicolumn{1}{|c|}{ Показатели эмоционального интеллекта } & $\begin{array}{c}\text { Естественный уровень } \\
\text { увлечения }\end{array}$ & $\begin{array}{c}\text { Средний уровень } \\
\text { увлечения }\end{array}$ & $\mathrm{t}-3$ нач. \\
\hline Эмоциональная осведомленность & 13,93 & 12,55 & 3,18 & 0,002 \\
\hline Управление своими эмоциями & 13,46 & 11,67 & 3,75 & 0,0003 \\
\hline Самомотивация & 13,18 & 11,69 & 3,04 & 0,003 \\
\hline Эмпатия & 12,75 & 11,22 & 2,80 & 0,006 \\
\hline Управление эмоциями других людей & 12,36 & 11,09 & 2,27 & 0,03 \\
\hline Уровень эмоционального интеллекта по Н. Холлу & 65,68 & 58,51 & 3,06 & 0,003 \\
\hline
\end{tabular}

Примечание: в таблице указаны результаты при р<0,05.

Таблица 2.

Результаты сравнений средних значений показателей эмоционального интеллекта подростков со средним уровнем увлечения и зависимостью от компьютерных игр

\begin{tabular}{|c|c|c|c|c|}
\hline Показатели эмоционального интеллекта & $\begin{array}{c}\text { Средний уровень } \\
\text { увлечения }\end{array}$ & Зависимость & t-знач. & p \\
\hline Внутриличностный эмоциональный интеллект & 44,91 & 38,12 & 2,31 & 0,02 \\
\hline Понимание эмоций & 41,71 & 35,76 & 2,42 & 0,02 \\
\hline Управление эмоциями & 44,89 & 39,47 & 2,05 & 0,04 \\
\hline Уровень эмоционального интеллекта по Д. В. Люсину & 86,60 & 75,35 & 2,43 & 0,02 \\
\hline Эмоциональная осведомленность & 12,55 & 10,88 & 2,75 & 0,007 \\
\hline Управление своими эмоциями & 11,67 & 9,41 & 3,23 & 0,002 \\
\hline Самомотивация & 11,69 & 8,94 & 3,87 & 0,0003 \\
\hline Эмпатия & 11,22 & 8,88 & 2,94 & 0,005 \\
\hline Управление эмоциями других людей & 11,09 & 8,24 & 3,48 & 0,0009 \\
\hline Уровень эмоционального интеллекта по Н. Холлу & 58,51 & 46,71 & 3,40 & 0,001 \\
\hline
\end{tabular}

Примечание: в таблице указаны результаты при р<0,05.

Таблица 3.

Результаты сравнений средних значений показателей эмоционального интеллекта подростков с естественным уровнем увлечения и зависимостью от компьютерных игр

\begin{tabular}{|c|c|c|c|c|}
\hline Показатели эмоционального интеллекта & $\begin{array}{c}\text { Естественный уровень } \\
\text { увлечения }\end{array}$ & Зависимость & t-знач. & p \\
\hline Межличностный эмоциональный интеллект & 43,82 & 37,11 & 2,31 & 0,03 \\
\hline Понимание эмоций & 42,96 & 35,76 & 2,53 & 0,02 \\
\hline Уровень эмоционального интеллекта по Д. В. Люсину & 87,75 & 75,35 & 2,43 & 0,02 \\
\hline Эмоциональная осведомленность & 13,93 & 10,88 & 4,74 & 0,0001 \\
\hline Управление своими эмоциями & 13,46 & 9,41 & 5,43 & 0,0001 \\
\hline Самомотивация & 13,18 & 8,94 & 5,80 & 0,0001 \\
\hline Эмпатия & 12,75 & 8,88 & 5,05 & 0,0001 \\
\hline Управление эмоциями других людей & 12,36 & 8,24 & 5,20 & 0,0001 \\
\hline Уровень эмоционального интеллекта по Н. Холлу & 65,68 & 46,71 & 5,64 & 0,0001 \\
\hline
\end{tabular}

Примечание: в таблице указаны результаты при р<0,05.

значимые социальные связи, что в итоге может привести к социальной дезадаптации или полной изоляции от других людей [7].

Результаты Таблицы 3 показывают, что при естественном уровне увлечения подростки имеют большее значение по показателям эмоционального интеллекта, чем подростки, зависимые от компьютерных игр. Зависимые от компьютерных игр подростки по сравнению с теми, кто лишь увлекается играми, обладают эмоциональной нестабильностью, что может приводить к потере взаимодействия с окружающими людьми, т.к. не понимают и не контролируют свои эмоциональные реакции, а также не могут проявлять понимание и сочувствие к окружаю- 
щим людям.

Подводя итог проведенного исследования, необходимо отметить, что эмоциональный интеллект подростков и отдельные его показатели различаются в зависимости от степени увлеченности компьютерными играми. Выдвинутая в исследовании гипотеза о том, что подростки, увлекающиеся компьютерными играми, обладают специфическими особенностями эмоционального интеллекта нашла свое подтверждение.

Выявленные различия в зависимости от степени увлечения обнаруживают себя в таких показателях эмоционального интеллекта как понимание своих переживаний и эмоций окружающих людей, а также способность к контролю и регуляции текущего эмоционального состояния.

Были выявлены следующие специфические особенности эмоционального интеллекта подростков с разной степенью увлеченности компьютерными играми:

- подростки, которые увлекаются компьютерными играми, имеют низкую способность понимать свои эмоции в конкретной ситуации, с трудом определяют эмоциональное состояние собеседника и редко замечают изменения в поведении других, реже задумываются о том, какие эмоции могут вызвать у окружающих людей высказанные слова или действия;

- чем больше подростки увлекаются компьютерными играми, тем ниже у них способность управлять интенсивностью испытываемых эмоций, выходить из отрицательных эмоциональных состояний и приглушать аффективные состояния, а также они обладают недостаточной способностью контролировать эмоции других людей. Зависимые от компьютерных игр подростки в меньшей степени могут осознавать свое эмоциональное состояние, недостаточно умеют контролировать интенсивность текущих эмоций, а также обладают более низкой способностью влиять на переживания других людей, т.к. не могут проявлять понимание и сочувствие к окружающим людям. Все это может отрицательно сказаться на способности подростков поддерживать и устанавливать значимые социальные связи.

- появление неконтролируемых эмоциональных всплесков со стороны подростка во время игрового процесса и неумение вовремя подавить эти всплески могут указывает на то, что продолжительная увлеченность компьютерными играми оказывает на подростка отрицательное воздействие.

Таким образом, исследование эмоционального интеллекта подростков с разной степенью увлеченности компьютерными играми позволит использовать полученные данные в целях профилактики патологической зависимости от компьютерных игр подростков и создания предпосылок к минимизации дезапдаптивных форм поведения подрастающего поколения посредством проведения просветительских мероприятий и лекций с родителями подростков и педагогами, работающими с данной возрастной категорией, а также проведения тематических бесед, тренингов и классных часов с подростками, увлекающихся компьютерными играми.

\section{ЛИТЕРАТУРА}

1. Андреева, И.Н. Азбука эмоционального интеллекта. / И.Н. Андреева. - СПб.: БХВ-Петербург, 2012. - 288 с.

2. Гоулман, Д. Эмоциональное лидерство: Искусство управления людьми на основе эмоционального интеллекта. / Д. Гоулман, Г. Бояцис, Э. Макки. М.: Альпина Паблишер, 2018. - 301 c.

3. Гребенникова, Н.В. Характерологические особенности старших подростков, склонных к компьютерно-игровой зависимости / Н.В. Гребенникова // Научные труды московского гуманитарного университета. - Москва. - 2017. - № 3. - С. 56-97.

4. Гришина, А.В. Тест-опросник степени увлеченности младших подростков компьютерными играми / А.В. Гришина // Вестник Московского университета. - Москва. - 2014. - № 4. - С. 131-141.

5. Демильханова, А.М. Влияние виртуальной реальности на образ Я (на примере ролевых компьютерных игр): дис. ... канд. психол. наук: 19.00 .05 / А.М. Демильханова. - Бишкек, 2009. - 137 с

6. Иванов, М.С. Психологические аспекты негативного влияния игровой компьютерной зависимости на личность человека / М.С. Иванов // Психология зависимости: хрестоматия / сост. К.В. Сельчонок. - Минск: Харвест, 2005. - С. 205-222.

7. Ильин, Е. И. Эмоции и чувства / Е. И. Ильин // Методика Н. Холла оценки «эмоционального интеллекта» (опросник ЕQ). - СПб.: Питер, 2001. - С. 633-634.

8. Лужкова, М.М. Игровая зависимость несовершеннолетних как причина социальной дезадаптации / М.М. Лужкова // Вестник науки и образования. Иваново. - 2019. - № 19 (73). - С. 105-109

9. Люсин, Д.В. Новая методика для измерения эмоционального интеллекта: опросник ЭмИн / Д.В. Люсин // Психологическая диагностика. - Москва. 2006. - № 4. - С. 3-18.

10. Люсин, Д.В. Современные представления об эмоциональном интеллекте / Д.В. Люсин // Социальный интеллект: теория, измерение, исследования. М.: Институт психологии РАН, 2004. - 176 с.

11. Манойлова, М.А. Развитие эмоционального интеллекта будущих педагогов. / М.А.. Манойлова. - Псков: ПГПИ, 2004. - 60 с. 
12. Никитина, Л.Н. Последствия чрезмерного увлечения компьютерными играми у несовершеннолетних / Л.Н. Никитина // АНИ: педагогика и психология. Тольятти. - 2016. - Т. 5. - № 2 (15). - С. 249-253.

13. Полякова, 0.0. Особенности компьютерной игровой активности подростков / 0.0. Полякова // Поволжский педагогический вестник. - Самара. - 2018. T. 6. - № 1 (18). - C. 55-59.

14. Психология зависимости: хрестоматия / сост. К.В. Сельченок. - Минск: Харвест, 2005. - 592 с.

15. Руслякова, Е.Е. Исследование уровня эмпатии у подростков, увлечённых компьютерными технологиями. Цифровая эмпатия / Е.Е. Руслякова, Э.А. Тимофеева, Ю.В. Шестакова, Д.А. Чепайкин // Мир науки. Педагогика и психология. - Москва. - 2020. - Т. 8. - № 6. - С. 131-141. URL: https://mirnauki.com/PDF/20PSMN620.pdf (доступ свободный).

16. Сергиенко, Е.А. Русскоязычная адаптация теста Дж. Мэйера, П. Сэловея, Д. Карузо «Эмоциональный интеллект» / Е.А. Серигиенко. - М.: Смысл, 2017. - 140 с.

17. Собкин, В.С. Подросток: виртуальная и социальная реальность / В.С. Собкин, Ю.М. Евстигнеева // Труды по социологии образования. - Т. 6. - Вып. 10. М.: Центр Социологии Образования РА0, 2001. - 156 с.

18. Тазетдинова, Ю.М. Теоретические предпосылки исследования особенностей агрессивного поведения у подростков-мальчиков с разным уровнем игровой компьютерной зависимости / Ю.М. Тазетдинова // Санкт-Петербургский образовательный вестник. - Санкт-Петербург. - 2018. - № 3 (19). - С. 43 -48.

19. Юрьева, Л.Н. Компьютерная зависимость: формирование, диагностика, коррекция и профилактика. / Л.Н. Юрьева, Т.Ю. Больбот.- Днепропетровск: Пороги, 2006. - 196 с.

( П Петроченко Ирина Алексеевна (Irina-Petrochenko22@yandex.ru), Щелин Игорь Владимирович (shchelin@rambler.ru).

Журнал «Современная наука: актуальные проблемы теории и практики»

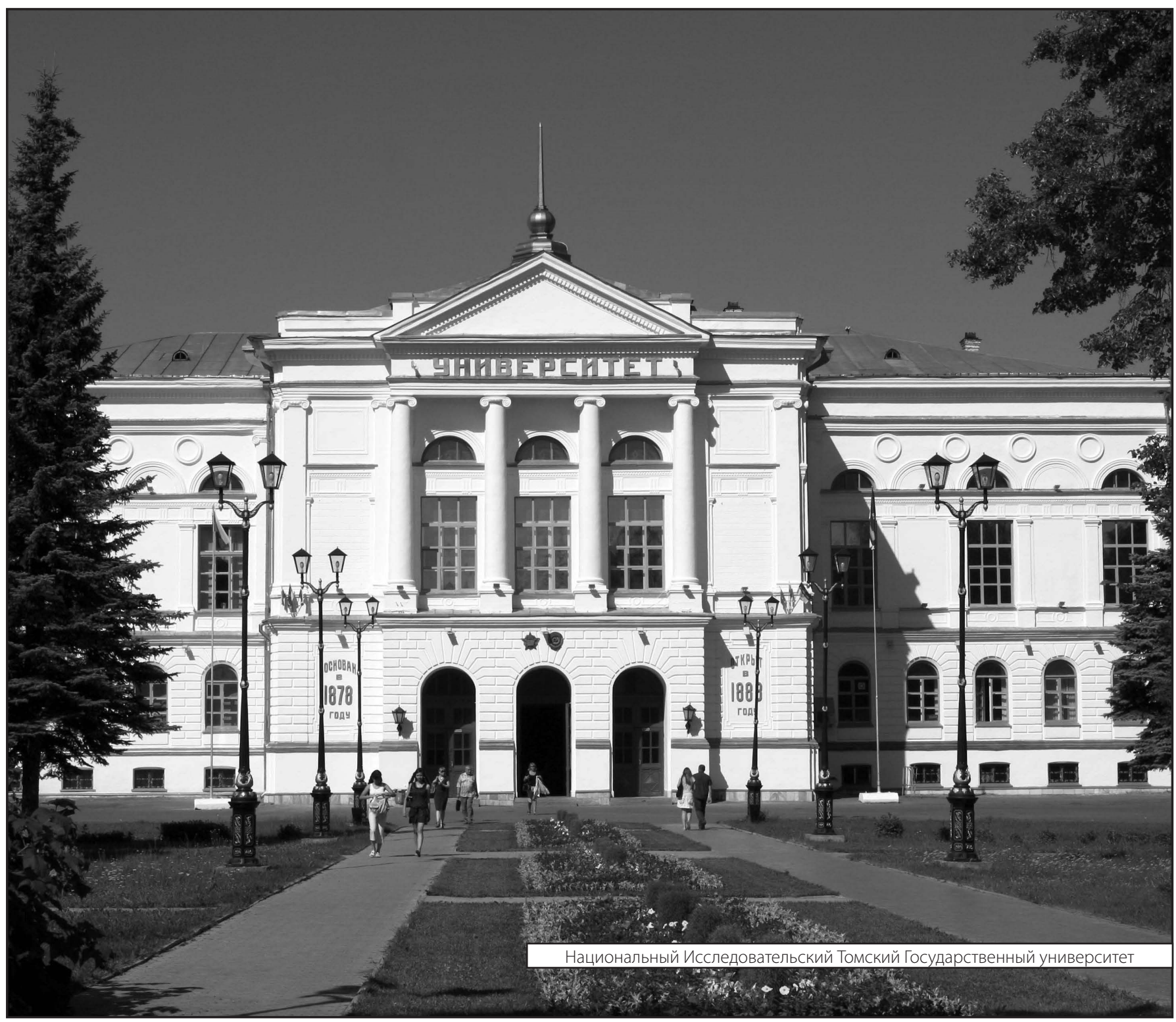

